\title{
A Brief Guide to Performing Pharmacological Studies In Vitro: Reflections from the EORTC-PAMM Course "Preclinical and Early-phase Clinical Pharmacology"
}

\author{
MJRIAM CAPULA ${ }^{1}$, CRISTINA CORNO ${ }^{2}$, BTISSAME EL HASSOUNI ${ }^{3}$, \\ GIOVANNA LI PETRI ${ }^{3,4}$ and SANDRA ARANĐELOVIĆ ${ }^{5}$, on Behalf of the EORTC PAMM Group \\ ${ }^{1}$ Fondazione Pisana per la Scienza-ONLUS, Pisa, Italy; \\ ${ }^{2}$ Molecular Pharmacology Unit, Department of Applied Research and Technological Development, \\ Fondazione IRCCS, Istituto Nazionale dei Tumori, Milan, Italy; \\ ${ }^{3}$ Amsterdam UMC, VU University of Amsterdam, Medical Oncology, \\ Cancer Center Amsterdam, Amsterdam, the Netherlands; \\ ${ }^{4}$ Department of Biological, Chemical and Pharmaceutical Sciences and Technologies (STEBICEF), \\ University of Palermo, Palermo, Italy; \\ ${ }^{5}$ Laboratory of Pharmacology, Department of Experimental Oncology, \\ Institute for Oncology and Radiology of Serbia, Belgrade, Serbia
}

\begin{abstract}
One aim of cell-based in vitro assays is to identify the best drug candidate to develop using the best tumor cell model. This is challenging in every anticancer drug discovery process. Briefly, we summarize the parameters to be taken into account when performing in vitro cell assays, in order to obtain reliable and reproducible results, which was fundamentally discussed by lecturers at the educational course on preclinical and early-phase clinical pharmacology studies, at the 40th Winter Meeting of the Pharmacology and Molecular Mechanisms Group of the European Organization for Research and Treatment of Cancer. Moreover, specific cellular sensitivity tests are described. In addition to monolayer in vitro cell models for the screening of new potential candidate drugs, three-dimensional tumor/cell tissue models are emerging as new pre-clinical tools that more closely reflect the in vivo microenvironment. Therefore, the use of different in vitro models for drug screening can enhance the predictability and reliability of preclinical drug-discovery phases and target validation.
\end{abstract}

Correspondence to: Sandra Aranđelović, Laboratory of Pharmacology, Department of Experimental Oncology, Institute for Oncology and Radiology of Serbia, Pasterova 14, 11000 Belgrade, Serbia. Tel: +381 112067287, Fax: +381 112685300, e-mail: manics@ncrc.ac.rs

Key Words: In vitro, cell-sensitivity assays, anticancer drugs, tumor cells, review.
Over the past decades conventional approaches to anticancer drug discovery have largely relied on screening for determining biological activity and deriving structure-activity relationships, with testing for improved drug efficacy, based on assays in immortalized cancer cell lines as the first preclinical step, which is simple and reliable (1-5). Mechanism-of-action studies of drug candidates are performed in vitro, using a wide variety of time- and cost-effective techniques in order to define which compounds should progress to the next stage in the drug development process. Monolayer cultures are the easiest and most 'controllable' models for the evaluation of drug potency for most cytotoxic agents. However, this simple model does not capture the complexity of the physiological microenvironment. It is becoming more and more evident that the tumor microenvironment is highly complex and heterogeneous, and that it plays a critical role in tumor cell dissemination and multidrug resistance $(6,7)$. Availability of high-throughput screening approaches and advances in genomics and proteomics are shifting standards of preclinical drug testing from empirical to target-based approaches, aimed at identifying genetic, transcriptional, and protein biomarkers of drug sensitivity and resistance $(8,9)$. Discovery of important signaling pathways and mutations that drive cancerous transformation lead to development of more selective drugs to combat cancer, such as tyrosine kinase inhibitors (gefitinib, erlotinib, osimertinib), poly (ADP-ribose) polymerase inhibitors (olaparib), proteasome inhibitors (bortezomib) and many monoclonal antibodies (trastuzumab, ramucirumab) (10-15). 
Table I. Factors influencing the reliability and reproducibility of in vitro experiments.

\begin{tabular}{ll}
\hline Drug solvent & - Incorrect solvent can influence drug stability, leading to inaccurate concentration determination \\
Drug concentration & - Final concentration of solvent should be non-toxic to cells \\
& - Pharmacologically/clinically relevant concentrations should be used for established drugs \\
Drug exposure duration & - Broad ranges can be used for initial screening with novel compounds, followed by a narrow range \\
& - Duration of drug exposure should match the in vivo situation \\
Seeding density and assay timing & - Metabolism of the drug should be taken into account
\end{tabular}

New knowledge has led investigators to incorporate a variety of cell lines and tumor cell-tissue models into the screening protocols of potential anticancer drug candidates, including cell lines harboring specific mutations, human tumor stem cells and endothelial cells lines $(16,17)$. There is a need for a better understanding of the complex interplay between cancer cells and neighboring cells, including stromal and immune system cells that lead to restructuration of the extracellular matrix and formation of chaotic vascularization structures, which eventually leads to metastasis. How tumor cells modulate their environment is of utmost relevance in defining efficient therapy strategies, as well as appropriate in vitro systems for drug evaluation $(18,19)$.

At the 40th Winter Meeting of The Pharmacology and Molecular Mechanisms (PAMM) Group of the European Organization for Research and Treatment of Cancer (EORTC), 2019., in Verona, Italy, the topics of the educational course on preclinical and early-phase clinical pharmacology studies addressed the new emerging concepts and current needs and challenges in preclinical drug investigation and therapeutics development. Utilization of in vitro, ex vivo, and in silico approaches in preclinical drug testing was thoroughly discussed by the presenters of the EORTC-PAMM Group (http://www.eortc.org/researchfield/pharmacology-molecularmechanisms). Herein, we briefly summarize the main criteria to be used in planning in vitro studies. The knowledge of basic concepts and awareness of troubleshooting in performing preclinical pharmacological studies in vitro are fundamental to producing reliable results.

\section{How to Perform Preclinical Pharmacological Studies In Vitro}

The measurement of drug dose-response in cultured cells is the cornerstone of preclinical assessment of anticancer drugs. High-throughput experimentation in multi-well plates, such as that carried out in the context of the NCI-60 program in which a panel of 60 different human tumor cell lines from nine different types of cancer were tested, is the most representative example of in vitro drug screening on a large-scale, with improved reproducibility (http://www.lincsproject.org) (20).
Considering that most research laboratories evaluate the activity of new compounds using few cell lines, utilization of suitable cellular models and appropriate chemosensitivity assay are of critical importance in achieving major goals and specifically in order to: a) identify new potential agents; b) determine their mechanism of action; c) understand the cellular response to the investigated drug $(3,21)$. Suggestions are to use cell lines with specific biological characteristics that match the rationale of compound design. More specifically, authenticated cell lines should be used to ensure the validity of the data. Authentication may be provided by short tandem repeat profiling, which is the analysis of microsatellite regions of DNA that have variable numbers of repeats and are located throughout the genome.

In many types of cancers, such as pancreatic, the subpopulation of cancer stem cells (CSCs) is highly enriched. CSCs are resistant to current chemotherapeutic drugs and therefore are thought to promote tumour recurrence $(22,23)$. CSCs are self-renewing tumor-initiating cells; in principle, they are good experimental models, but they need to be well characterized with appropriate markers. Immortalized human umbilical vein endothelial cells, which express integrin subunits consistent with an endothelial origin, and transformed human umbilical vein endothelial cells (EA.hy 926) provide valuable in vitro models for studying molecular mechanisms underlying endothelial cell proliferation and migration during tumor metastasis $(17,24)$. Among the basic conditions related to the investigated tumor cell lines that should be predetermined and recorded as part of the dose-response measurement are plating density, and the proliferative rate/cell-doubling time. The impact of the type and volume of medium used, should be determined empirically for each cell line prior to study and should be set so as to have as little effect as possible, on growth rate over the incubation period.

\section{Performing Reliable Cell-Survival and Cell Growth-inhibition Assays}

Although simple in principle, cell-based assays are subject to a variety of factors that can affect the results, making data unreliable (examples are listed in Table I). Thus, basics 
principles have to be followed when designing and performing cell-based assays in vitro (3).

Performing reliable cell-survival assays requires careful control over key pharmacological parameters that affect the proliferative rate of tumor cells in vitro. Suggestions are to carefully account for a) an appropriate drug solvent; b) pharmacologically relevant drug concentrations for established drugs and novel compounds; c) duration of drug exposure that would match the in vivo situation (e.g. reflecting time of plasma peaks and drug persistence); d) optimization of cell-seeding density and assay timing to the particular cell-doubling time.

Choosing an appropriate drug solvent is critical in that a solvent may influence the stability of the drug. Attention should be paid so that solvents are used at concentrations that are nontoxic for the cells. If the compound is stable once dissolved, it can be stocked at low temperature $\left(-20^{\circ} \mathrm{C},-80^{\circ} \mathrm{C}\right)$, otherwise it has to be freshly dissolved prior to use. It is also important to know if a compound shows protein binding and if this is reversible. Dimethyl sulfoxide [DMSO, $\mathrm{O}=\mathrm{S}(\mathrm{CH} 3) 2$ ], is viewed as a 'universal' solvent able to solubilize most small molecules at high concentrations (up to $100 \mathrm{mmol} / \mathrm{l}$ ). However, using DMSO as a solvent might be inappropriate (25). It should also be recognized whether the tested compound is a pro-drug and whether it can be substituted for the active metabolite. For metal-based drugs such as $\mathrm{Pt}(\mathrm{II})$ or $\mathrm{Ru}(\mathrm{II})$ complexes, in aqueous solution exchange of the anionic (halide) ligands is considered as a part of complex activation (26). Activation of organometallic ruthenium pro-drugs by substitution reactions under physiological (intracellular) conditions enhances their reactivity with nucleophilic targets in cells, such as DNA. However, the drug needs to be stable throughout storage and the experiment, particularly as continuous exposure may lead to drug (chemical) breakdown. Stability in a particular solvent (DMSO, saline) may be determined by nuclear magnetic resonance (NMR) spectroscopy in order to confirm that structures of complexes in solution do not change over time, for example, that coordinated ligands remain at the same position around the metal center $(26,27)$.

In order to determine the approximate range of drug sensitivity for the cell lines under study, it is often advisable to run a preliminary experiment. When no prior information is available, the standard approach should be to perform cellsensitivity assays, using serial dilutions of the tested drug, at concentrations ranging from $10 \mathrm{nM}$ to $100 \mu \mathrm{M}$, with half$\log 10$ steps (28). Dose-response studies should be followed by analysis of more narrowly spaced concentrations around the responsive range. The process of reliably and accurately treating cells with drug is not inconsequential. It is highly recommended to carry out the relevant experiments, using clinically meaningful concentrations with a standard agent as reference, and comparative activity against non-cancer cells is desirable. High drug concentrations should only be used for a short treatment duration.

\section{In Vitro Cell-Sensitivity Assays}

Two key pharmacological parameters that determine cellular response are the concentration $(\mathrm{C})$ of a drug and the duration of drug exposure $(\mathrm{T})(3,20)$. For conventional cytotoxic agents, cell proliferation and survival in monolayer (2D) cultures are usually proportional to the product of $\mathrm{C} \times \mathrm{T}$, with the exception of drugs that are cell-cycle phase-specific, where cellular response above a threshold concentration is typically proportional to exposure (29).

Time-dependent measurement that reveal changes in response over time, adapted to plate-based experiments, can be performed using various approaches. The achievement of reliable, relevant and reproducible results depends on the selection of an appropriate assay, and experimental design. The choice of the specific cell-sensitivity assay should be made so that the endpoint of the assay addresses the experimental question correctly.

The colony-forming assay, in which the clonogenic capability of cells is evaluated, represents the gold standard of cell-sensitivity assays. Cells are considered clonogenic if they maintain the capacity to proliferate indefinitely and to form a clone or colony (Figure 1A) (16). Untreated cells plated as a single-cell suspension at low densities (2-50 cells $/ \mathrm{cm}^{2}$ ) can generate colonies. The loss of reproductive integrity can be related to the antitumor activity of compounds by a curve where survival is expressed as a function of drug concentration. Critical parameters for this type of assay are: Plating efficiency $(\mathrm{PE})=$ ratio of the number of colonies to the number of cells seeded; surviving fraction $(\mathrm{SF})=$ number of colonies after treatment of cells expressed in terms of PE.

There are multiple methods for determining cell sensitivity to drugs based on cell ability to either bind, exclude or metabolize certain dyes, such as those in assays using trypan blue exclusion, sulforhodamine $B(\mathrm{SRB})$, tetrazolium or resazurine reduction, and ATP content.

(i) In the tetrazolium reduction assay, [3-(4,5dimethylthiazol-2-yl)-2,5 diphenyltetrazolium bromide] (MTT), the most commonly utilized of the tetrazolium family, is added to cultures in which the viable (metabolically active cells), are able to convert these compounds into colored formazan products, that can be colorimetrically detected at $570 \mathrm{~nm}$, with a microplate reader (Figure 1B) (30). Assay conditions need to be standardized for each cell line, as formazan production varies depending on the cell line and on cell number.

(ii) The SRB assay is a rapid and sensitive method utilizing a bright pink anionic dye that binds electrostatically to the basic amino acids of trichloroacetic acid (TCA)-fixed cells (Figure 1B) (31). The protein-bound dye is extracted with Tris base [tris (hydroxymethyl) aminomethane], after washing off the unbound dye, and the protein content can be 


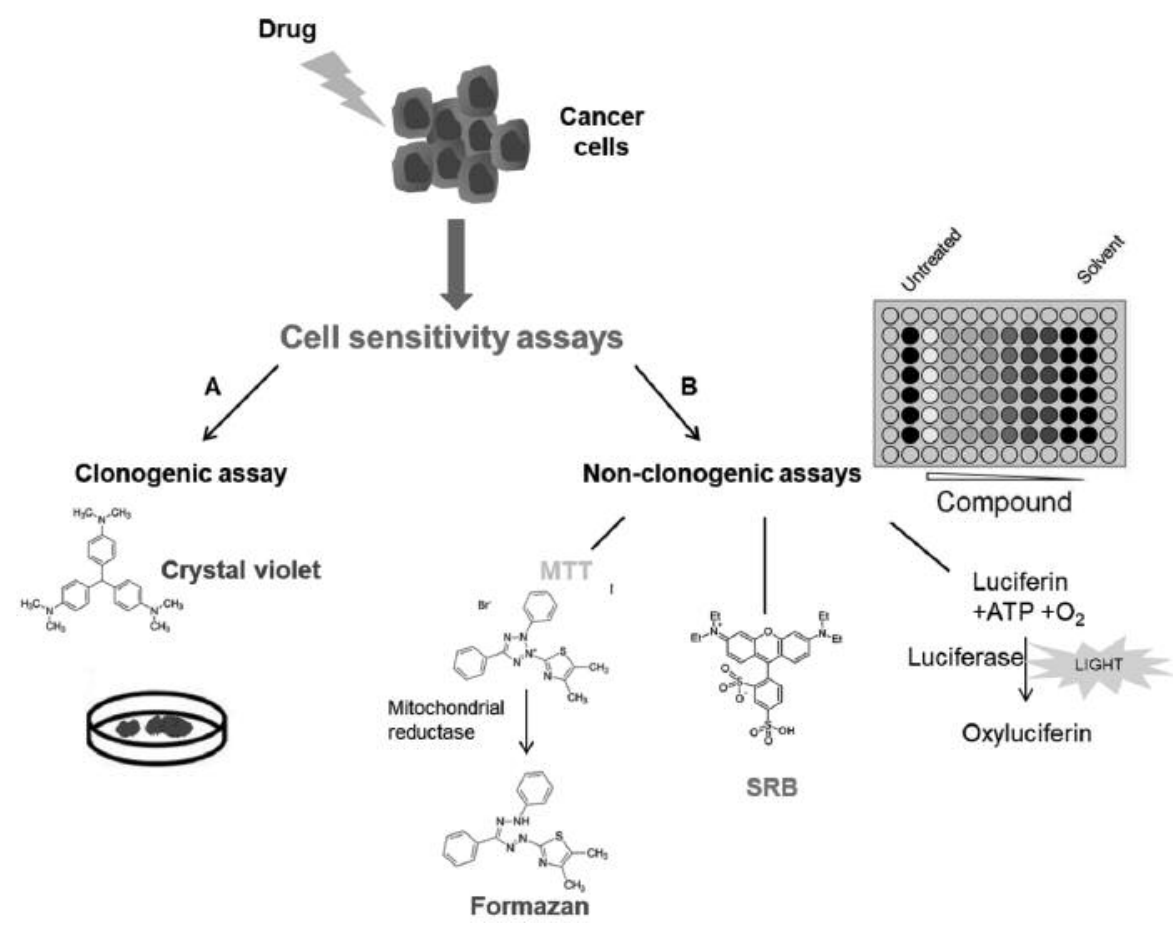

Figure 1. Schematic representation of cell-sensitivity assays. The most common assays used to evaluate the sensitivity of tumor cells to anticancer drugs are shown. Clonogenic assays comprise the analysis of the ability of a compound to inhibit the formation of cell colonies on plastic or agar (A). Non-clonogenic assays are the most commonly employed cell-sensitivity assays with an endpoint different from clonogenic capability (B).

quantified colorimetrically at $550 \mathrm{~nm}$ with a microplate reader. The endpoint of SRB assay is nondestructive, not time critical (stable) and comparable with those of other assays. Although labor-intensive with several washing steps, it offers a practical advantage of high-throughout screening of anticancer drugs, and the results obtained with the SRB assay are not significantly different from those obtained with the MTT assay (30).

(iii) The ATP content assay is based on the key role of ATP in cellular biological processes as the main carrier of energy in cells and on the relationship between ATP concentration in all living cells and cell biomass. When the cellular membrane loses its integrity, the ability to produce ATP is also lost and the remaining ATP is quickly consumed by endogenous ATP-ases. Therefore, the ATP assay is used to assess cell viability through high-throughput screening platforms using an ATP detection kit.

When these assays are used, the following parameters can be obtained: $\mathrm{IC}_{50}$ : Concentration of agent that inhibits cell growth/survival (in the case of colony-forming assay) by $50 \%$; GI50: agent concentration which inhibits growth by $50 \%$; TGI: total growth inhibition; $\mathrm{LC}_{50}$ : concentration leading to death of $50 \%$ initially seeded cells, the lethal concentration (see https://dtp.cancer.gov/discovery_development/nci-60/ methodology.htlm) (Figure 2).

\section{Quality Control of Cell Culture}

The most frequent type of contamination of cell cultures in vitro is Mycoplasma, representing over 20\% among culture contaminants (32). These bacteria belong to the order of Mollicutes, characterized by the lack of a cell wall, and affect cellular physiology. Mycoplasma can pass through filters (220 $\mathrm{nm}$ pores), the source of contamination being most often other cultures, serum, feeder layers, and infected personnel. A few techniques are available to detect Mycoplasma contamination such as growth in broth, staining (e.g., 4',6-diamidino-2-phenylindole, DAPI), polymerase chain reaction, and ATP luminometry. As well as cell line authentication by short tandem repeat analysis, detection of Mycoplasma contamination should be a routine test when running cell pharmacology assays (33).

\section{Conclusion}

The use of 2D cell-culture systems for the discovery of new anticancer drugs represents a simple, reliable and economical approach in pre-clinical phases, and provides important information about drug activity, in terms of growth inhibition potency and cytotoxicity. However, this kind of assays do not consider the complexity of the tumor microenvironment, 

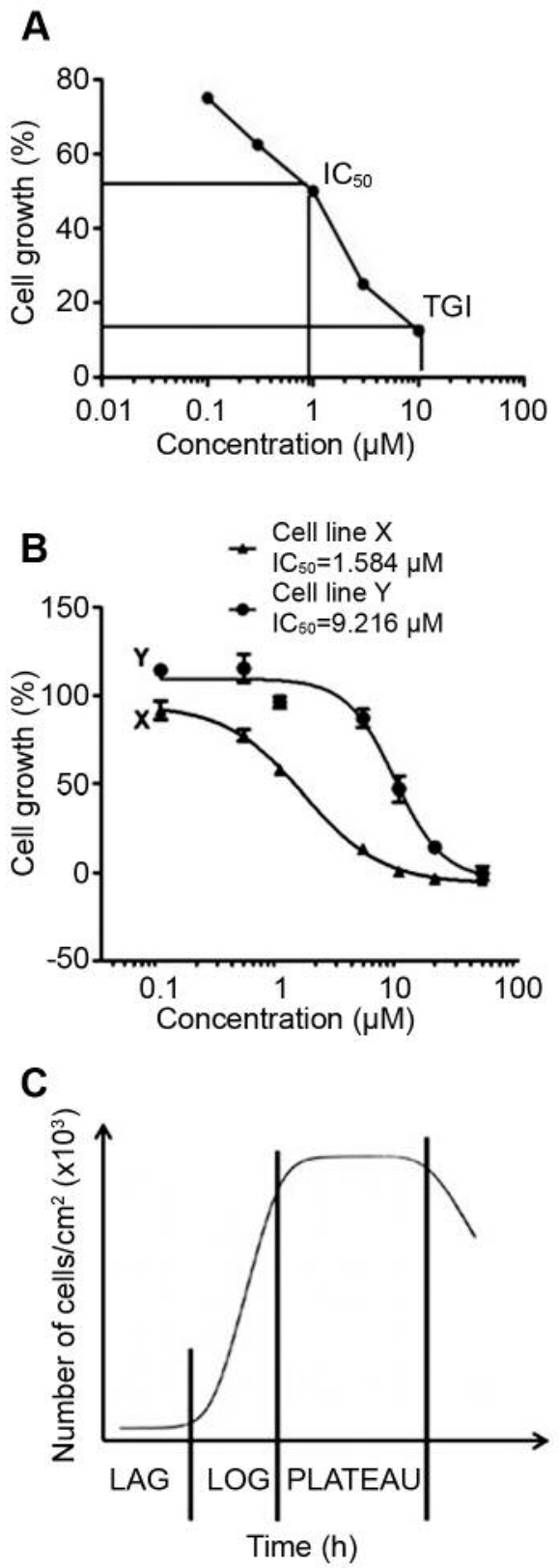

Figure 2. Graphical representation of relevant cell-pharmacological parameters. A: Representative plot from a cell-sensitivity assay where cell growth inhibition is measured. Concentration that inhibits cell growth by $50 \%\left(I C_{50}\right)$, and total growth inhibition $(T G B)$ values are determined from the plot. B: Plots of drug concentration-dependent decrease of cell growth (\%) for two different tumor cell lines $(X, Y)$. C: The different phases of tumor cell growth in monolayer culture and drug-free medium are shown.

often inducing different responses to the same treatment in in vitro and in vivo tests. Through the cooperative work of cell biologists and bioengineers, new scaffolds for 3D tumor cell/tissue growth have been generated. Multicellular spheroids and organoids also represent valuable models for use in cellular pharmacology studies, exploitable even in coculture approaches. They mimick the in vivo cellular microenvironment, taking into account the influence of specific parameters on drug response, including the physical and mechanical properties of the extracellular matrix, the oxygen gradient, extracellular $\mathrm{pH}$ and gradient of nutrients, as well as drug transport. Although some obstacles must be overcome, such as the use of suitable coating matrices, 3D cultures are considered useful future tools for obtaining more reliable results in pre-clinical trials for high-throughput screening in the drug discovery and target validation.

\section{Conflicts of Interest}

The Authors wish to confirm that there are no known conflicts of interest associated with this publication and there has been no significant financial support for this work that could have influenced its outcome.

\section{Authors' Contributions}

All Authors made equal and substantial contributions to conception, design and writing of the article.

\section{Acknowledgements}

This review article was prepared on behalf of the EORTC-PAMM Group, the Organizing Committee of the EORT-PAMM winter meeting and the Educational Course on Pre-clinical Pharmacology of Anticancer Drugs 2019, Verona, Italy.

\section{References}

1 Kelland LR: Preclinical perspectives on platinum resistance. Drugs 59(4): 37-38, 2000. PMID: 108642.

2 Ziegler CJ, Silverman AP and Lippard SJ: High-throughput synthesis and screening of platinum drug candidates. J Biol Inorg Chem 5(6): 774-783, 2000. PMID: 11129005.

3 Perego P, Hempel G, Linder S, Bradshaw TD, Larsen AK, Peters GJ and Phillips RM: EORTC PAMM Group. Cellular pharmacology studies of anticancer agents: recommendations from the EORTC-PAMM Group. Cancer Chemother Pharmacol 81: 427441, 2018. PMID: 29285635. DOI: 10.1007/s00280-017-3502-7

4 Giovannetti E, Zucali PA, Assaraf YG, Leon LG, Smid K, Alecci C, Giancola F, Destro A, Gianoncelli L, Lorenzi E, Roncalli M, Santoro A and Peters GJ: Preclinical emergence of vandetanib as a potent antitumour agent in mesothelioma: molecular mechanisms underlying its synergistic interaction with pemetrexed and carboplatin. Br J Cancer 105: 1542-1553, 2011. PMID: 21970874. DOI: 10.1038/bjc.2011.400

5 Massihnia D, Avan A, Funel N, Maftouh M, van Krieken A, Granchi C, Raktoe R, Boggi U, Aicher B, Minutolo F, Russo A, Leon LG, Peters GJ and Giovannetti E: Phospho-Akt overexpression is prognostic and can be used to tailor the synergistic interaction of Akt inhibitors with gemcitabine in pancreatic cancer. J Hematol Oncol 10: 9, 2017. PMID: 28061880. DOI: 10.1186/s13045-016-0371-1 
6 van Beijnum JR, Giovannetti E, Poel D, Nowak-Sliwinska P and Griffioen AW: miRNAs: Micro-managers of anticancer combination therapies. Angiogenesis 20(2): 269-285, 2017. PMID: 28474282. DOI: $10.1007 / \mathrm{s} 10456-017-9545-\mathrm{x}$

7 Phillips RM: Targeting the hypoxic fraction of tumours using hypoxia-activated prodrugs. Cancer Chemother Pharmacol 77(3): 441-457, 2016. PMID: 26811177. DOI: 10.1007/s00280015-2920-7

8 Roma-Rodrigues C, Mendes R, Baptista PV and Fernandes AR: Targeting tumor microenvironment for cancer therapy. Int J Mol Sci 20(4): 840, 2019. DOI: 10.3390/ijms20040840.

9 Castagna A, Antonioli P, Astner H, Hamdan M, Righetti SC, Perego P, Zunino F and Righetti PG: A proteomic approach to cisplatin resistance in the cervix squamous cell carcinoma cell line A431. Proteomics 4(10): 3246-3267, 2004. PMID: 153786 90. DOI: $10.1002 /$ pmic. 200400835

10 Burger A.M: Highlights in experimental therapeutics. Cancer Lett 245(1-2): 11-21, 2007. PMID: 16647200. DOI: 10.1016/ j.canlet.2006.03.012

11 Erdem L, Giovannetti E, Leon LG, Honeywell R and Peters GJ: Polymorphisms to predict outcome to the tyrosine kinase inhibitors gefitinib, erlotinib, sorafenib and sunitinib. Curr Top Med Chem 12(15): 1649-59, 2012. PMID: 22978339.

12 Lamb YN and Scott LJ: Osimertinib: A review on T790M-positive advanced non-small cell lung cancer. Target Oncol 12(4): 555562, 2017. PMID: 28710746. DOI: 10.1007/s11523-017-0519-0

13 Evers B, Schut, van der Burg E, Braumuller TM, Egan DA, Holstege H, Edser P, Adams DJ, Wade-Martins R, Bouwman P and Jonkers J: A high-throughput pharmaceutical screen identifies compounds with specific toxicity against BRCA2deficient tumors. Clin Cancer Res 16(1): 99-108, 2010. PMID: 20008842. DOI: 10.1158/1078-0432.CCR-09-2434

14 Gatti L, Zuco V, Zaffaroni N and Perego P: Drug combinations with proteasome inhibitors in antitumor therapy. Curr Pharm Des 19(22): 4094-114, 2013. PMID: 23181571.

15 Gatti L, Benedetti V, De Cesare M, Corna E, Cincinelli R, Zaffaroni N, Zunino F and Perego P: Synergistic interaction between the novel histone deacetylase inhibitor ST2782 and the proteasome inhibitor bortezomib in platinum-sensitive and resistant ovarian carcinoma cells. J Inorg Biochem 113: 94-101, 2012. PMID: 22717676. DOI: 10.1016/j.jinorgbio.2012.04.007

16 Hamburger AW and Salmon SE: Primary bioassay of human tumor stem cells. Science 197(4302): 461-463, 1977. PMID: 560061.

17 Rhim JS, Tsai WP, Chen ZQ, Chen Z, Van Waes C, Burger AM and Lautenberger JA: A human vascular endothelial cell model to study angiogenesis and tumorigenesis. Carcinogenesis 19(4): 673-681, 1998. PMID: 9600354.

18 Langhans SA: Three-dimensional in vitro cell culture models in drug discovery and drug repositioning. Front Pharmacol 9, 2018. PMID: 29410625. DOI: 10.3389/fphar.2018.00006

19 Mebarki M, Bennaceur A and Bonhomme-Faivre L: Human-cellderived organoids as a new ex vivo model for drug assays in oncology. Drug Discov Today 23: 857-863, 2018. PMID: 29428171. DOI: $10.1016 /$ j.drudis.2018.02.003

$20 \mathrm{Su}$ G, Burant CF, Beecher CW, Athey BD and Meng F: Integrated metabolome and transriptome analysis of the NCI60 dataset. BMC Bioinformatics 12(suppl 1): 36, 2011. PMID: 21342567. DOI: 10.1186/1471-2105-12-S1-S36

21 Kumar S, Bajaj S and Bodla RB: Preclinical screening methods in cancer. Indian J Pharmacol 48(5): 481-486, 2016. PMID: 27721530. DOI: $10.4103 / 0253-7613.190716$
22 Avan A, Quint K, Nicolini F, Funel N, Frampton AE, Maftouh M, Pelliccioni S, Schuurhuis GJ, Peters GJ and Giovannetti E: Enhancement of the antiproliferative activity of gemcitabine by modulation of c-MET pathway in pancreatic cancer. Curr Pharm Des 19(5): 940-950, 2013. PMID: 22973962.

23 Bertolini G, D'Amico L, Moro M, Landoni E, Perego P, Miceli R3, Gatti L, Andriani F, Wong D, Caserini R, Tortoreto M, Milione M, Ferracini R, Mariani L, Pastorino U, Roato I, Sozzi $\mathrm{G}$ and Roz L: Microenvironment-modulated metastatic CD133+/CXCR4+/EpCAM ${ }^{-}$lung cancer-initiating cells sustain tumor dissemination and correlate with poor prognosis. Cancer Res 75(17): 3636-3649, 2015. PMID: 26141860. DOI: 10.1158/0008-5472.CAN-14-3781

24 Filipović L, Aranđelović S, Krivokuća A, Janković R, Dojčinović B and Radulović S: Trans-platinum(II)/(IV) complexes with acetylpyridine ligands as antivascular agents in vitro: Cytotoxic and antiangiogenic potential. Anticancer Agents Med Chem 16(12): 1628-1639, 2016. PMID: 27102278.

25 Hall MD, Telma KA, Chang KE, Lee TD, Madigan JP, Lloyd JR, Goldlust IS, Hoeschele JD and Gottesman MM: Say no to DMSO: Dimethylsulfoxide inactivates cisplatin, carboplatin, and other platinum complexes. Cancer Res 74(14): 3913-3922, 2014. PMID: 24812268. DOI: 10.1158/0008-5472.CAN-14-0247

26 Patra M, Joshi T, Pierroz V, Ingram K, Kaiser M, Ferrari S, Spingler B, Keiser $\mathrm{J}$ and Gasser G: DMSO-mediated ligand dissociation: renaissance for biological activity of $N$-heterocyclic$\left[\mathrm{Ru}(\eta 6-\right.$ arene $\left.) \mathrm{Cl}_{2}\right]$ drug candidates. Chemistry 19(44): 1476814772, 2013. PMID: 24123460. DOI: 10.1002/ chem.201303341

27 Nikolić S, Opsenica DM, Filipović V, Dojčinović B, Aranđelović $\mathrm{S}$, Radulović S and Grgurić-Šipka S: Strong in vitro cytotoxic potential of new ruthenium-cymene complexes. Organometallics 34(14): 3464-3473, 2015. DOI: 10.1021/acs.organomet.5b00041

28 Boyd MR: The NCI in vitro anticancer drug discovery screen concept, implementation and operation 1985-1995. In: Anticancer Drug Development Guide Preclinical Screening, Clinical Trials and Approval. Teicher BA and Andrews PA (eds.) New York, Humana Press, pp. 23-42, 2004.

29 Kavallaris M: Microtubules and resistance to tubulin-binding agents. Nat Rev Cancer 10(3): 194-204, 2010. PMID: 20147901. DOI: $10.1038 / \mathrm{nrc} 2803$

30 Supino R: MTT assays. Methods Mol Biol 43: 137-149, 1995. PMID: 7550641. DOI: 10.1385/0-89603-282-5:137

31 Skehan P, Storeng R, Scudiero D, Monks A, McMahon J, Vistica D, Warren JT, Bokesch H, Kenney S and Boyd MR: New colorimetric cytotoxicity assay for anticancer-drug screening. J Natl Cancer Inst 82(13): 1107-1112, 1990. PMID: 2359136.

32 Drexler HG and Uphoff CC: Mycoplasma contamination of cell cultures: Incidence, sources, effects, detection, elimination. Cytotechnology 39: 75-90, 2002. PMID: 19003295. DOI: 10.1023/A: 1022913015916

33 Molla Kazemiha V, Amanzadeh A, Memarnejadian A, Azari S, Shokrgozar MA, Mahdian R and Bonakdar S: Sensitivity of biochemical test in comparison with other methods for the detection of Mycoplasma contamination in human and animal cell lines stored in the National Cell Bank of Iran. Cytotechnology 66: 861-873, 2014. PMID: 24493067. DOI: 10.1007/s10616-013-9640-9

Received May 8, 2019

Revised June 4, 2019

Accepted June 7, 2019 